\title{
Bone mineral density in patients with chronic obstructive pulmonary disease treated with budesonide Turbuhaler $\AA$
}

\author{
O. Johnell*, R. Pauwels\#, C-G. Löfdahl", L.A. Laitinen ${ }^{+}$, D.S. Postma ${ }^{\S}$, N.B. Pride ${ }^{f}$, S.V. Ohlsson**
}

Bone mineral density in patients with chronic obstructive pulmonary disease treated with budesonide Turbuhaler $\mathbb{R}$. O. Johnell, R. Pauwels, C-G. Löfdahl, L.A. Laitinen, D.S. Postma, N.B. Pride, S.V. Ohlsson. C ERS Journals Ltd 2002.

ABSTRACT: There is a need for studying the effects of long-term inhaled corticosteroid therapy on bone mineral density (BMD) and vertebral fracture rates in patients with mild chronic obstructive pulmonary disease (COPD).

Patients ( $n=912$, mean age 52 yrs) with mild COPD (mean forced expiratory volume in one second (FEV1) $77 \%$ of predicted; mean FEV1/slow vital capacity ratio $62 \%$ ) were randomized to receive budesonide $400 \mu \mathrm{g}$, or placebo twice daily via Turbuhaler $\mathbb{R}$. BMD was measured at the L2-L4 vertebrae and the femoral neck, trochanter and Ward's triangle by dual-energy X-ray absorptiometry at baseline and after 6, 12, 24 and 36 months $(n=161)$. Radiographs of the thoracic and lumbar spine were obtained at the beginning and end of treatment $(n=653)$.

Previous fractures were present at baseline in 43 budesonide-treated patients (13.4\%) and 38 placebo-treated patients $(11.5 \%)$. New fractures occurred in five budesonidetreated patients, compared with three in the placebo group $(\mathrm{p}=0.50)$. There were no significant changes in BMD at any site in budesonide-treated patients, compared with the placebo group, during the course of the study. Budesonide treatment was associated with a slight but statistically significant decrease in the area under the concentrationtime curve for serum osteocalcin.

In the present study, involving a large group of patients with chronic obstructive pulmonary disease, long-term treatment with budesonide $800 \mu \mathrm{g} \cdot \mathrm{day}^{-1}$ via

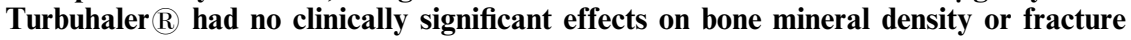
rates.

Eur Respir J 2002; 19: 1058-1063.
*Dept of Orthopaedics, Malmö University Hospital, Malmö, Sweden. \#Dept of Respiratory Diseases, Ghent University Hospital, Ghent, Belgium. "Dept of Respiratory Medicine, University Hospital, Lund, Sweden. ${ }^{+}$Dept of Medicine, University Central Hospital, Helsinki, Finland. ${ }^{\S}$ Division of Respiratory Disease, University Hospital, Groningen, the Netherlands. ${ }^{f}$ Respiratory Division, Imperial College School of Medicine, Hammersmith Hospital, London, UK. **AstraZeneca, Lund, Sweden.

Correspondence: O. Johnell, Dept of Orthopaedics, UMAS, S-205 02 Malmö, Sweden.

Fax: 4640336227

E-mail: olof.Johnell@orto.mas.lu.se

Keywords: Bone mineral density, budesonide, chronic obstructive pulmonary disease, drug safety, fractures, inhaled steroids

Received: August 282001

Accepted after revision December 27 2001

This study was supported by AstraZeneca Research and Development Lund, Lund, Sweden.
Oral corticosteroid treatment is a recognized risk factor for bone loss and osteoporosis [1]. Some crosssectional studies using high doses of inhaled corticosteroids have also reported decreases in bone mineral density (BMD) or biochemical markers of bone formation [2-5], whereas others have found little or no effect [6-10]. Such studies, however, are subject to confounding by factors such as previous oral steroid treatment, age, sex, and alcohol or tobacco use. Moreover, short-term changes in biochemical markers of bone metabolism are not necessarily predictive of long-term changes in bone turnover [11]. The importance of long-term prospective studies using specific measures of bone status, such as bone densitometry or fracture rates, to assess the effects of inhaled corticosteroids on bone has been emphasized [11], but relatively few studies have been performed to date. There may also be important differences between inhaled steroids. A comparison of data from 10 controlled studies, in which patients received inhaled corticosteroid therapy for between 6 months and
10.1 yrs, concluded that fluticasone propionate may exert a greater effect on bone density than other inhaled steroids [12].

The European Respiratory Society Study on Chronic Obstructive Pulmonary Disease (EUROSCOP) was a 3-yr international prospective trial that compared the effects of the inhaled corticosteroid budesonide (Pulmicort $\AA$ Turbuhaler $\AA$, AstraZeneca R\&D Lund, Lund, Sweden) and placebo in patients with chronic obstructive pulmonary disease (COPD) who continued to smoke throughout the study [13]. In view of the known adverse effects of oral corticosteroid therapy, this study included an extensive safety evaluation programme to document the long-term safety and tolerability of inhaled corticosteroid therapy in COPD. This programme included spinal radiography and, in some centres, measurements of BMD by dual-energy X-ray absorptiometry. Since both COPD and smoking are themselves risk factors for osteoporosis [1, 14], EUROSCOP provided a valuable opportunity to evaluate the impact of long-term 
inhaled corticosteroid therapy on bone density and metabolism in a population at risk of osteoporosis. The radiographical and BMD data from patients who completed the study are presented in this paper.

\section{Methods}

\section{Study design}

EUROSCOP was a randomized, double-blind, placebo-controlled parallel-group study performed at 39 centres in nine European countries (Belgium, Denmark, Finland, Italy, the Netherlands, Norway, Spain, Sweden and the UK). It was conducted according to the principles of the Declaration of Helsinki and was approved by regulatory and ethics committees at all centres. Written informed consent was obtained from all subjects before inclusion in the study.

Details of the study have been presented in full elsewhere [13]. In brief, patients with mild COPD (mean forced expiratory volume in one second (FEV1) $77 \%$ of predicted; mean $\mathrm{FEV} 1 / \mathrm{slow}$ vital capacity ratio $62 \%$ ) underwent a 3-month smoking cessation programme followed by a 3-month run-in period during which compliance with inhaled placebo was assessed. At the end of this period, patients who continued to smoke and showed $\geqslant 75 \%$ compliance with inhaled medication were randomized to receive budesonide $400 \mu \mathrm{g}$ or placebo twice daily via the dry powder

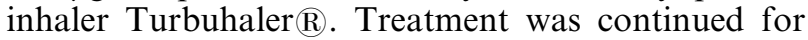
3 yrs. Patients with a history of asthma, allergic rhinitis or allergic eczema were excluded from the study, as were those who had received oral corticosteroids for $>4$ weeks during the preceding 6 months.

\section{Bone mineral density measurements}

In nine centres, BMD was measured by dual-energy X-ray absorptiometry (DEXA) at baseline and after $6,12,24$ and 36 months. Measurements were made from the lumbar vertebrae L2-L4, and the neck, trochanter and Ward's triangle of the left femur. BMD was calculated by dividing the bone mineral content derived from the DEXA scans by the area.

All measurements were made using either a Hologic QDR-1000 (Hologic, Waltham, MA, USA) or a Lunar DPX-L (Lunar (GE), Madison, WI, USA) densitometer. The performance of the instruments was assessed at baseline and then monthly throughout the study by an external organization (Bona Fide, Madison, WI, USA). All scans were then reviewed by one of the authors (O. Johnell).

\section{Spinal radiography}

Radiographs of the thoracic and lumbar spine were obtained at the start of randomized treatment and after 36 months of treatment. Radiographs were obtained with the patient in the left lateral supine position, according to standardized protocols for exposure time and film-focus distance. The anterior, posterior and medial heights of the vertebrae T4-T12 and L1-L4 were determined from the radiographs. The presence or absence of vertebral fractures at baseline was determined by comparing each patient's baseline vertebral height ratio with reference values. A new vertebral fracture was defined as a reduction of $\geqslant 20 \%$, with an absolute decrease of $\geqslant 4 \mathrm{~mm}$, in the height of any vertebral body between baseline and the end of treatment [15]. All radiographs were analysed at the Dept of Orthopaedics, Malmö University Hospital, Sweden, by a central evaluator who was unaware of the medication received. Analyses were performed according to a standardized computerized protocol.

\section{Osteocalcin measurement}

Venous blood samples $(10 \mathrm{~mL})$ were obtained at baseline and after $6,12,24$ and 36 months treatment. The samples were allowed to clot at room temperature for 60 min and serum was separated by centrifugation for $10 \mathrm{~min}$ at $1350 \times \mathrm{g}$. Serum was stored at $-20^{\circ} \mathrm{C}$ or lower prior to analysis. Serum osteocalcin concentrations were measured by CAP using commercially available kits (Pharmacia \& UpJohn Diagnostics, Uppsala, Sweden). The coefficient of variation of the assay ranged from $5.0-15.7 \%$ for sample concentrations of $\sim 5-14 \mu \mathrm{g} \cdot \mathrm{L}^{-1}$.

\section{Statistical methods}

Statistical analysis of the radiographical and BMD data focused on the completed patient population, defined as those patients who completed 3 yrs treatment and had radiographs and DEXA scans taken within 60 days of the baseline and end-of-treatment assessments. The primary end-point was the percentage change in BMD from baseline to the end of treatment. Changes in BMD were analysed by analysis of variance (ANOVA), with treatment, centre and sex as factors in the model. Age at the start of the study and baseline BMD were covariates.

The proportion of patients in each group with new vertebral fractures on spinal radiography was compared by Fisher's Exact test. Homogeneity of the corresponding odds ratios (OR) for males and females was evaluated by means of the Breslow-Day test.

Serum osteocalcin data were expressed as the area under the concentration-time curve (AUC). Timeaveraged AUCs were analysed using a multiplicative model: $\log ($ AUC $)=$ treatment + centre $+\log ($ baseline $)$.

\section{Results}

\section{Patient demographics}

Of the 912 patients who completed $3 \mathrm{yrs}$ of treatment, 653 (322 in the budesonide group, 331 in the placebo group) had spinal radiographs taken at baseline and at the end of treatment, and 161 (82 in the budesonide group, 79 in the placebo group) had 
Table 1. - Baseline demographic characteristics of the radiograph $(n=653)$, dual-energy X-ray absorptiometry (DEXA, $n=161)$ and overall $(n=912)$ study populations

\begin{tabular}{|c|c|c|c|c|c|c|}
\hline & \multicolumn{2}{|c|}{ Radiograph } & \multicolumn{2}{|c|}{ DEXA } & \multicolumn{2}{|c|}{ Overall study population } \\
\hline & Budesonide & Placebo & Budesonide & Placebo & Budesonide & Placebo \\
\hline Subjects n & 322 & 331 & 82 & 79 & 458 & 454 \\
\hline Age yrs & $52(31-65)$ & $52(25-65)$ & $54(31-64)$ & $53(36-64)$ & $52(31-65)$ & $52(25-65)$ \\
\hline Height $\mathrm{cm}$ & $173.0(152-194)$ & $172.9(150-198)$ & $172.3(155-189)$ & $172.1(154-192)$ & $172.8(152-194)$ & $172.8(150-198)$ \\
\hline Weight kg & $75.5(41-121)$ & $73.7(43-125)$ & $77.4(50-117)$ & $74.8(50-110)$ & $74.9(41-121)$ & $73.6(43-125)$ \\
\hline $\begin{array}{l}\text { Duration of } \\
\text { smoking yrs }\end{array}$ & $35.5(11-52)$ & $35.7(9-56)$ & $36.2(11-50)$ & $36.4(20-51)$ & $36.0(11-52)$ & $36.0(9-56)$ \\
\hline $\begin{array}{l}\text { Total consumption } \\
\mathrm{g} \cdot \mathrm{day}^{-1}\end{array}$ & $14.8(1.5-45)$ & $13.5(0.8-103.1)$ & $16.1(1.5-33.8)$ & $16.3(3.8-52.5)$ & $15.0(1.5-88.7)$ & $13.7(0.8-103.1)$ \\
\hline Cigarettes $\cdot$ day $^{-1}$ & $19.3(0-60)$ & $17.1(0-70)$ & $21.0(0-45)$ & $20.9(3-70)$ & $19.1(0-60)$ & $17.6(0-70)$ \\
\hline
\end{tabular}

Data are presented as mean (range).

DEXA performed at the same times. The demographic characteristics of these patients are summarized in table 1 . Both the radiography and DEXA populations were comparable with the overall study population [13] in terms of baseline demographics.

\section{Vertebral fractures}

One centre changed radiographical equipment during the course of the study, and hence it was not possible to compare baseline and end-of-treatment radiographs. Patients from this centre $(n=16)$ were excluded from the analysis.

Previous fractures were present at baseline in 81 patients $(12.4 \%)$, of whom $43(13.4 \%)$ were in the budesonide group and $38(11.5 \%)$ were in the placebo group. The time between radiographs varied from 972-1,177 days, with a mean of 1,091 days in both groups. At the end of treatment, new fractures were observed in five patients $(1.55 \%)$ in the budesonide group and three patients $(0.91 \%)$ in the placebo group. The incidence of new fractures in male patients was $1.73 \%$ in the budesonide group and $0.42 \%$ in the placebo group. Analysis of the OR between male and female patients did not show significant heterogeneity. Overall, there was no significant difference in the incidence of new fractures between the groups $(\mathrm{p}=0.50)$.

Table 2.-Baseline bone mineral density in patients for whom both baseline and end-of-treatment scans were available $(n=16)$

\begin{tabular}{lcc}
\hline & Budesonide & Placebo \\
\hline Subjects n & 82 & 79 \\
Femoral neck & $0.89 \pm 0.15$ & $0.85 \pm 0.16$ \\
$\mathrm{~g} \cdot \mathrm{cm}^{-2}$ & $(0.59-1.26)$ & $(0.57-1.33)$ \\
Femoral & $0.79 \pm 0.16$ & $0.77 \pm 0.17$ \\
$\quad$ trochanter $\mathrm{g} \cdot \mathrm{cm}^{-2}$ & $(0.38-1.21)$ & $(0.45-1.22)$ \\
Femoral Ward's & $0.69 \pm 0.19$ & $0.66 \pm 0.20$ \\
triangle $\mathrm{g}^{-2} \mathrm{~cm}^{-2}$ & $(0.35-1.14)$ & $(0.31-1.27)$ \\
$\mathrm{L} 2-\mathrm{L} 4 \mathrm{~g} \cdot \mathrm{cm}^{-2}$ & $1.09 \pm 0.17$ & $1.06 \pm 0.19$ \\
& $(0.58-1.59)$ & $(0.67-1.60)$ \\
\hline
\end{tabular}

Data are presented as mean \pm SD (range).

\section{Bone mineral density}

Baseline BMD values in the 161 patients in whom both baseline and end-of-treatment DEXA scans were performed are summarized in table 2 . There were no significant differences between BMD values in these patients and those in the entire completed patient population. Mean BMD values at the end of the study are shown in table 3 and changes in BMD during the course of the study are shown in figure 1. At each site studied, the $95 \%$ confidence interval (CI) for the difference between treatments overlapped zero, indicating that the difference was not statistically significant (table 4).

\section{Osteocalcin concentrations}

The geometric mean concentrations of osteocalcin at baseline and time-averaged AUCs at the end of treatment were $4.78 \mu \mathrm{g} \cdot \mathrm{L}^{-1}$ and $5.03 \mu \mathrm{g} \cdot \mathrm{L}^{-1}$, respectively, in the budesonide group and $4.74 \mu \mathrm{g} \cdot \mathrm{L}^{-1}$ and $5.37 \mu \mathrm{g} \cdot \mathrm{L}^{-1}$, respectively, in the placebo group. The estimated ratio of the treatment effects (budesonide/ placebo) was $93.0 \%$ (95\% CI 88.7-97.5, p=0.0025), but there was no significant difference in serum osteocalcin concentrations between the groups after 3 yrs. The geometric mean AUCs at 3 yrs were $5.03 \mu \mathrm{g} \cdot \mathrm{L}^{-1}$ in the budesonide group and $5.37 \mu \mathrm{g} \cdot \mathrm{L}^{-1}$ in the placebo group.

Table 3.-Baseline bone mineral density at the end of the study

\begin{tabular}{lcc}
\hline & Budesonide & Placebo \\
\hline Subjects n & 78 & 71 \\
Femoral neck & $0.88 \pm 0.15$ & $0.85 \pm 0.15$ \\
$\mathrm{~g} \cdot \mathrm{cm}^{-2}$ & $(0.57-1.27)$ & $(0.54-1.29)$ \\
Femoral & $0.78 \pm 0.16$ & $0.77 \pm 0.17$ \\
$\quad$ trochanter $\mathrm{g} \cdot \mathrm{cm}^{-2}$ & $(0.33-1.19)$ & $(0.48-1.22)$ \\
Femoral Ward's & $0.68 \pm 0.18$ & $0.66 \pm 0.18$ \\
$\quad$ triangle g.cm & $(0.30-1.12)$ & $(0.34-1.20)$ \\
$\mathrm{L} 2-\mathrm{L} 4 \mathrm{~g} \cdot \mathrm{cm}^{-2}$ & $1.09 \pm 0.19$ & $1.06 \pm 0.19$ \\
& $(0.56-1.68)^{\#}$ & $(0.70-1.61)^{\bullet}$ \\
\hline
\end{tabular}

Data are presented as mean \pm SD (range). ${ }^{*}: \mathrm{n}=82 ;{ }^{\bullet}: \mathrm{n}=79$. 
a)

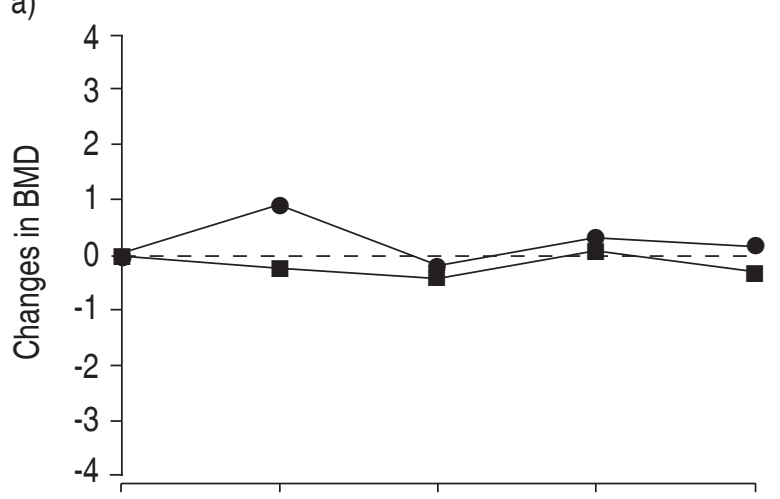

c)

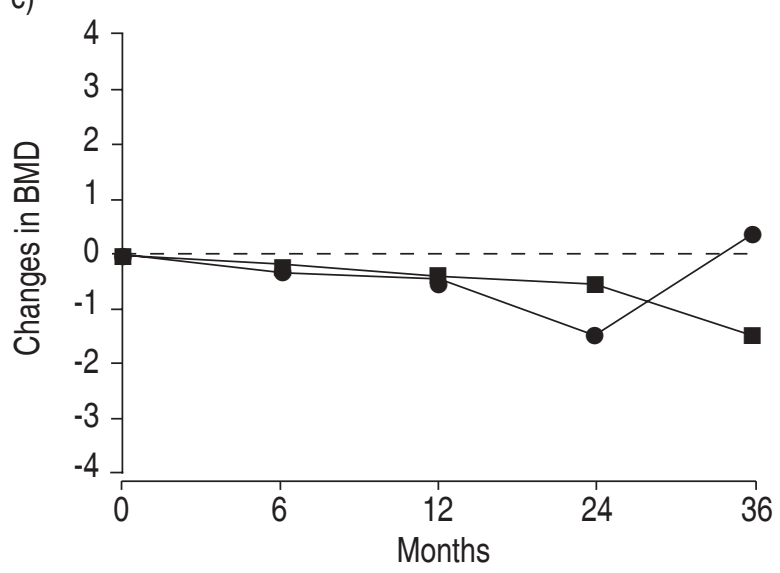

b)

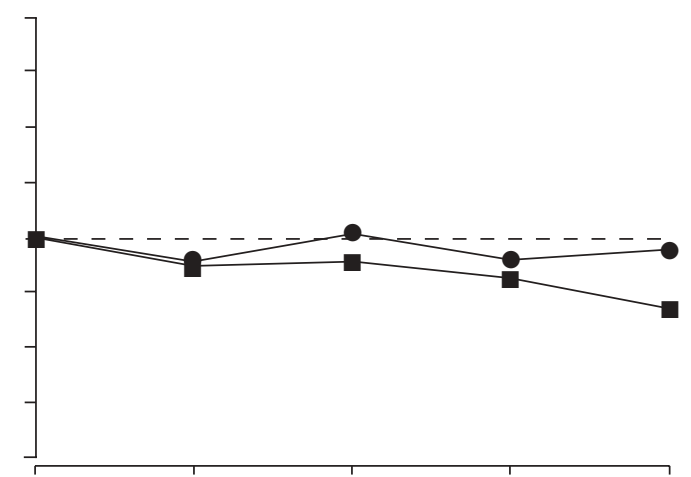

d)

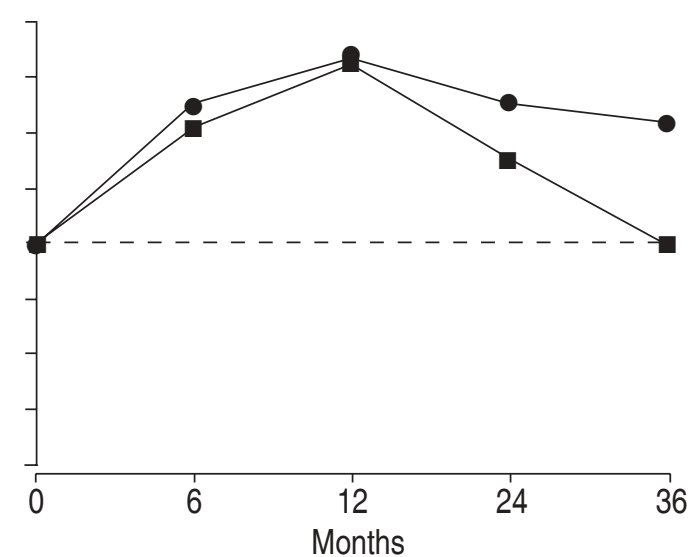

Fig. 1.-Mean changes in bone mineral density (BMD) during the study, measured in a) lumbar spine (L2-L4), b) femoral neck, c) femoral trochanter and d) femoral Ward's triangle. $\mathbf{\square}$ : budesonide $400 \mu \mathrm{g}$ b.i.d.; $\bullet$ : placebo.

\section{Discussion}

EUROSCOP is one of the largest longitudinal studies of the effects of inhaled corticosteroids on bone to have been completed to date. Most previous studies have been cross-sectional in design and have yielded conflicting results [2-10]. One longitudinal study in elderly subjects has shown accelerated bone loss in subjects treated with glucocorticosteroids, but only 40 subjects received steroid therapy and it was not possible to distinguish between any effect of inhaled steroids and that of oral therapy [16]. In EUROSCOP, patients with a significant history of

Table 4. - Estimated difference in treatment effects on bone mineral density (budesonide and placebo)

\begin{tabular}{lcccc}
\hline & $\begin{array}{c}\text { Estimated } \\
\text { difference }\end{array}$ & $\begin{array}{c}\text { Lower } \\
95 \% \text { CI }\end{array}$ & $\begin{array}{c}\text { Upper } \\
95 \% \text { CI }\end{array}$ & p-value \\
\hline $\begin{array}{l}\text { L2-L4 \% change } \\
\text { Femoral neck \% } \\
\text { change }\end{array}$ & -0.52 & -1.91 & 0.88 & 0.4667 \\
$\begin{array}{c}\text { Femoral trochanter } \\
\text { \% change }\end{array}$ & -1.62 & -2.58 & 0.85 & 0.3205 \\
$\begin{array}{c}\text { Femoral Ward's } \\
\text { triangle \% change }\end{array}$ & -1.67 & -4.84 & 0.25 & 0.0895 \\
\hline
\end{tabular}

CI: Confidence interval. oral steroid treatment were excluded, as were patients with asthma or allergic rhinitis, who might previously have received long-term inhaled steroid therapy. Thus, confounding by previous steroid therapy can be excluded. Bone status was assessed objectively, by measurement of BMD and fracture rates, as recommended by KersTJENS et al. [11]. The statistical analysis described in this paper focused on patients who completed $3 \mathrm{yrs}$ of treatment because the inclusion of discontinued patients might have introduced bias, since the time course of any effect of inhaled steroids on bone metabolism was not known.

The results of the study showed that there were no significant differences in BMD or fracture rate between budesonide-treated and placebo-treated patients with COPD. Airway disease and smoking are both risk factors for bone loss [17, 18], hence the finding that long-term inhaled budesonide therapy does not exacerbate this process is reassuring.

The present findings are in contrast with recent data from the Lung Health Study (LHS) II, which involved 559 patients with moderately severe COPD (mean FEV1 64\% pred; mean FEV1/forced vital capacity ratio $57 \%$ ). In this study, treatment with triamcinolone acetonide $1,200 \mu \mathrm{g} \cdot \mathrm{day}^{-1}$ for 4 yrs was associated with a statistically significant $2 \%$ reduction in BMD in the femoral neck, compared with placebo [19]. Thus, comparison of the EUROSCOP and LHS II 
results would support the view that inhaled steroids may show significant differences in their systemic effects, and hence in their effects on bone metabolism, or that these effects may be dose-dependent [12]. In general, for steroids such as budesonide, triamcinolone and fluticasone that undergo extensive first-pass metabolism in the gut, the inhaled fraction of the dose will be the principal determinant of systemic activity, but factors such as topical potency and receptorresidency time also contribute [12]. Since the systemic adverse effects of inhaled steroids generally increase with dose, whereas dose/response efficacy relationships are relatively flat, increasing the dose of inhaled steroid may result in a significant increase in the risk of systemic effects while providing little further therapeutic benefit [12].

The findings of EUROSCOP are consistent with those of large prospective trials of long-term budesonide therapy in asthmatic patients. For example, in a study by TATTERSFIELD et al. [20], BMD and vertebral fractures were monitored in 374 adult patients with mild asthma who were treated for 2 yrs with budesonide Turbuhaler $\AA$, beclomethasone dipropionate (BDP) pressurized metered dose inhaler, or reference therapy that did not include inhaled steroids. Steroid doses were adjusted during the trial according to the asthma control achieved. The final mean doses were $513 \mu \mathrm{g} \cdot \mathrm{day}^{-1}$ for budesonide and $614 \mu \mathrm{g} \cdot \mathrm{day}^{-1}$ for BDP. There was no significant difference between the groups in the mean change in BMD during the study. There was a significant correlation between change in BMD and dose of inhaled steroid, but this may have been attributable to confounding by asthma severity, since there was also a correlation between BMD and morning peak expiratory flow rates.

The EUROSCOP findings are also consistent with those of a long-term study in a large cohort of children who received inhaled budesonide, at a mean daily dose of $412 \mu \mathrm{g}$ for $\sim 10 \mathrm{yrs}$ [21]. In a group of these children, BMD was measured by DEXA during treatment with budesonide for 3-6 yrs at a mean daily dose of $504 \mu \mathrm{g}$ [22]. BMD in these children was consistently within the range seen in a control group of children who had never received inhaled steroids.

In the present study, budesonide treatment was associated with a slight decrease in osteocalcin AUC (normally considered a marker of bone formation), compared with placebo. The significance of such changes is unclear since there was no significant change in BMD [9, 11, 12, 23]. In a study by TATTERSFIELD et al. [24], osteocalcin concentrations increased slightly in the budesonide and reference therapy groups but remained unchanged in the BDP group, whereas concentrations of deoxypyrodinoline and pyrodinoline cross-links (markers of bone turnover) decreased slightly in the budesonide and reference therapy groups but remained unchanged in the BDP group. The difference in osteocalcin AUC between the BDP and reference therapy groups was statistically significant. These findings are consistent with those of short-term ( $\leqslant 1 \mathrm{yr})$ studies that have shown greater effects on bone markers with BDP than with budesonide [25, 26]. In a previous study [11], osteocalcin concentrations showed an initial decrease during short-term (4 weeks) treatment with inhaled steroids, but markers of bone formation were increased during long-term (2.5 yrs) treatment. Thus, shortterm changes in individual bone markers are not predictive of long-term changes in bone turnover.

The lack of effect of budesonide on BMD is consistent with the lack of effect of this steroid on growth in children. In the long-term study previously described [21], the final height attained by budesonidetreated children was not significantly different from the predicted height, and there was no correlation between the difference between attained and predicted height and the cumulative dose or duration of budesonide treatment. The final height attained correlated significantly with the child's height before budesonide treatment, which in turn was significantly correlated with lung function, reflecting the fact that severity of asthma may itself influence growth. Such findings suggest that long-term therapy with inhaled budesonide has no clinically relevant effects on bone metabolism or growth in children: the reductions in growth reported in some previous studies [27-29] appear to be confined to the first 1-2 yrs of treatment, and catch-up growth occurs thereafter. This conclusion is consistent with the results of the recent Childhood Asthma Management Research Programme [30], in which the mean increase in height was significantly reduced during the first year in children receiving budesonide, compared with placebo-treated children, but the difference had disappeared by the second year.

In conclusion, the results of the European Respiratory Society Study on Chronic Obstructive Pulmonary Disease show that long-term treatment with inhaled budesonide, at a dose of $800 \mu \mathrm{g} \cdot \mathrm{day}^{-1}$, has no significant effect on bone mineral density or fracture rate in patients with chronic obstructive pulmonary disease.

\footnotetext{
Acknowledgements. The authors would like to thank K. Önnby for measuring spinal heights.
}

\section{References}

1. Picado C, Luengo M. Corticosteroid-induced bone loss. Prevention and management. Drug Safety 1996; 15: 347-359.

2. Hanania NA, Chapman KR, Sturtridge WC, Szalai JP, Kesten S. Dose-related decrease in bone density among asthmatic patients treated with inhaled corticosteroids. J Allergy Clin Immunol 1995; 96: 571-579.

3. Packe GE, Robb O, Robins SP, Reid DM, Douglas JG. Bone density in asthmatic patients taking inhaled corticosteroids: comparison of budesonide and beclomethasone dipropionate. J Roy Coll Phys Lond 1996; 30: 128-132.

4. Ebeling PR, Erbas B, Hopper JL, Wark JD, Rubinfeld AR. Bone mineral density and bone turnover in asthmatics treated with long-term inhaled or oral glucocorticoids. J Bone Min Res 1998; 13: 1283-1289.

5. Wong CA, Walsh LJ, Smith CJP, et al. Inhaled 
corticosteroid use and bone-mineral density in patients with asthma. Lancet 2000; 355: 1399-1403.

6. Ayres JG, Bateman ED, Lundback B, Harris TAJ. High dose fluticasone propionate $1 \mathrm{mg}$ daily versus fluticasone propionate $2 \mathrm{mg}$ daily or budesonide $1.6 \mathrm{mg}$ daily, in patients with chronic severe asthma. Eur Respir J 1995; 8: 579-586.

7. Medici TC, Grebski E, Hacki M, Ruegsegger P, Maden C, Efthimiou J. Effect of one year treatment with inhaled fluticasone propionate or beclomethasone dipropionate on bone density and bone metabolism: a randomised parallel group study in adult asthmatic subjects. Thorax 2000; 55: 375-382.

8. Egan JJ, Maden C, Kalra S, Adams JE, Eastell R, Woodcock AA. A randomized, double-blind study comparing the effects of beclomethasone and fluticasone on bone density over two years. Eur Respir $J$ 1999; 13: 1267-1275.

9. Boulet LP, Milot J, Gagnon L, Poubelle PE, Brown J. Long-term influence of inhaled corticosteroids on bone metabolism and density. Are biological markers predictors of bone loss? Am J Respir Crit Care Med 1999; 159: 838-844.

10. Herrala J, Puolijoki H, Impivaara O, Liippo K, Tala $\mathrm{E}$, Nieminen MM. Bone mineral density in asthmatic women on high-dose inhaled beclomethasone dipropionate. Bone 1994; 15: 621-623.

11. Kerstjens HAM, Postma DS, van Doormaal JJ, et al. Effects of short term and long term treatment with inhaled corticosteroids on bone metabolism in patients with airways obstruction. Thorax 1994; 49: 652-656.

12. Lipworth BJ. Systemic adverse effects of inhaled corticosteroid therapy. A systematic review and metaanalysis. Arch Intern Med 1999; 159: 941-955.

13. Pauwels RA, Löfdahl C-G, Laitinen LA, et al. Longterm treatment with inhaled budesonide in persons with mild chronic obstructive pulmonary disease who continue smoking. N Engl J Med 1999; 340: 19481953.

14. Praet JP, Peretz A, Rozenberg S, Famaey JP, Bourdoux P. Risk of osteoporosis in men with chronic bronchitis. Osteoporosis Int 1992; 2: 257-261.

15. Liebermann UA. Effect of oral alendronate on bone mineral density and the incidence of fractures in postmenopausal osteoporosis - for the Alendronate Phase III Osteoporosis Treatment Group. $N$ Engl J Med 1995; 333: 1437-1443.

16. Saito JK, Davis JW, Wasnich RD, Ross PD. Users of low-dose glucocorticoids have increased bone loss rates: a longitudinal study. Calcif Tissue Int 1995; 57 : 115-119.

17. Lau EMC, Li M, Woo J, Lai C. Bone mineral density and body composition in patients with airflow obstruction - the role of inhaled steroid therapy, disease and lifestyle. Clin Exp Allergy 1998; 28: 1066-1071.
18. Iqbal F, Michaelson J, Thaler L, Rubin J, Roman J, Nanes MS. Declining bone mass in men with chronic pulmonary disease - contribution of glucocorticoid treatment, body mass index and gonadal function. Chest 1999; 116: 1616-1624.

19. Lung Health Study Research Group. Effect of inhaled triamcinolone on the decline in pulmonary function in chronic obstructive pulmonary disease. $N$ Engl J Med 2000; 343: 1902-1909.

20. Tattersfield AE, Aubier M, Braillon P, et al. Longterm effects on bone mineral density (BMD) by inhaled steroids (IS) compared with non-steroid reference therapy. Am J Respir Crit Care Med 1998; 157: A408.

21. Agertoft L, Pedersen S. Effect of long-term treatment with inhaled budesonide on adult height in children with asthma. N Engl J Med 2000; 343: 1064-1069.

22. Agertoft L, Pedersen S. Bone mineral density in children with asthma receiving long-term treatment with inhaled budesonide. Am J Respir Crit Care Med 1998; 157: 178-183.

23. Efthimiou J, Barnes PJ. Effect of inhaled corticosteroids on bones and growth. Eur Respir J 1998; 11: $1167-1177$.

24. Tattersfield AE, Town I, Johnell O, et al. Bone mineral density in subjects with mild asthma randomised to treatment with inhaled corticosteroids or non-corticosteroid treatment for two years. Thorax 2001; 56: 272-278.

25. Birkebaek NH, Esberg G, Andersen K, Wolthers O, Hassager C. Bone and collagen turnover during treatment with inhaled dry powder budesonide and beclomethasone dipropionate. Arch Dis Child 1995; 73: 524-527.

26. Struijs A, Mulder H. The effects of inhaled glucocorticoids on bone mass and biochemical markers of bone homeostasis: a 1-year study of beclomethasone versus budesonide. Netherlands J Med 1997; 50: 233237.

27. Saha MT, Laippala P, Lenko HL. Growth of asthmatic children is slower during than before treatment with inhaled glucocorticoids. Acta Paediatr 1997; 86: 138-142.

28. Doull IJ, Campbell MJ, Holgate ST. Duration of growth suppressive effects of regular inhaled corticosteroids. Arch Dis Child 1998; 78: 172-173.

29. Simons FE. A comparison of beclomethasone, salmeterol, and placebo in children with asthma. Canadian Beclomethasone Dipropionate-Salmeterol Xinafoate Study Group. N Engl J Med 1997; 337: 1659-1665.

30. The Childhood Asthma Management Program Research Group. Long-term effects of budesonide or nedocromil in children with asthma. $N$ Engl $\mathrm{J} \mathrm{Med}$ 2000; 343: 1054-1063. 